\title{
INTERVIEW WITH OCKE-SCHWEN BOHN
}

\author{
Walcir Cardoso ${ }^{1}$ \\ Ubiratã Kickhöfel Alves
}

We are honored to report an interview that we conducted with Professor Ocke-Schwen Bohn, from Aarhus University (Denmark). Dr. Bohn is worldwide famous for his work on second language (L2) learning of phonetics and phonology with groundbreaking research in the field, as reflected in his numerous publications. Dr. Bohn is also organizing the next edition of the International Symposium on the Acquisition of Second Language Speech (New Sounds), which is scheduled to take place in June 2016, at Aarhus University in Denmark. In what follows, Dr. Bohn talks about his career, his views on the phonetic-phonological acquisition of L2s, and what he is preparing for us for the forthcoming 2016 edition of New Sounds in Aarhus, a city that almost never sleeps during the summer - read the interview for details.

\section{Interviewers:}

Could you tell us about your career as a specialist in second/foreign language (L2) speech? Why, how and when did you choose this field? What are the advantages and challenges of being an L2 speech specialist?

\section{Professor Ocke Bohn:}

Luck, and being in the right place at the right time, have been important ingredients in my career. When I started university as a very young student at Kiel University in Germany, everyone else appeared so much smarter and so much more knowledgeable. I did not really know what it meant to study English, and I was very pleasantly surprised to find that one of the first semester courses, English Phonetics, was just my cup of tea, which was to a large extent due to the fact that we had a very talented and enthusiastic teacher with a rather bizarre sense of humor.

I did fairly well in the English Linguistics courses, so I took the courage and applied (successfully) for a job as student research assistant working

1 Department of Education - Concordia University, Canada.

2 Instituto de Letras - Universidade Federal do Rio Grande do Sul, Brasil. 
on Henning Wode's second language acquisition project at Kiel University. Wode was one of the pioneers of second language acquisition research. At that time, in the mid-seventies, there was only a handful of places at which this kind of research took place. And I was lucky enough to be at one of them! My job consisted mostly of transcribing (orthographically and phonetically) spontaneous conversations of child L2 learners from reel-to-reel tapes, which was actually more interesting than it sounds. Apart from Henning Wode and a small number of senior researchers, there was this gang of approximately 20 undergraduate and graduate students who felt that they were part of something really new and exciting. No matter what kind of data we analyzed or transcribed, we were probably the first ever to find out which stages German learners of English went through when they learned, for example, how to negate English sentences, or how to produce, say, English /r/.

My work with Wode and under his guidance was interrupted by a oneyear grant from the German government which allowed me to study at the University of California at Berkeley (UCB). Now, nearly 40 years later, when all university education has to fit into the inflexible designs of narrowminded administrators, it sounds incredible that I could spend this year taking just about any kind of course (I was not part of a degree program at UCB), which I perhaps could then use for credit at my home university in Kiel - or not. So I sat in on courses on language acquisition (Slobin, ErvinTripp, Lily Fillmore), in Linguistics (the Lakoffs and Charles Fillmore), and Philosophy (Feyerabend). For reasons that I still don't understand, I stayed away from phonetics - maybe it appeared too intimidating and demanding.

When I returned to Kiel, I stayed with L2 syntax, in which I wrote both my Master's thesis and my $\mathrm{PhD}$ dissertation. I was still trying to find my bearings after I received my $\mathrm{PhD}$ degree, when Henning Wode showed me a letter that James Flege had sent him (in the late 80s people still wrote letters), and in which he asked whether Wode knew anyone who might like to apply for a postdoc position with Jim. Well, I certainly did. I had never heard of Jim Flege before, but I had developed quite some interest in phonetics (and become somewhat disenchanted with syntax). I applied, and Jim was courageous (foolhardy?) enough to offer me the job, so I became Jim Flege's first postdoc.

My gratitude to Jim Flege is humongous. It was Jim from whom I learned how to conduct L2 speech research, and everything that I have done since then is directly or indirectly owed to the two years I spent as his postdoc 
in Birmingham, Alabama. This is especially true of the contacts which I established in those years or sometime after, and which lead to long-term research collaborations with colleagues from which I also learned a lot. In chronological order: Winifred Strange, Linda Polka, Catherine Best, Terry Gottfried, Diane Kewley-Port.

You asked about the advantages and challenges of being an L2 speech specialist. In my experience, the challenges are mainly bureaucratic and institutional, especially for someone like me who works in the humanities. I think that things have changed a bit, but when I returned from Birmingham to Kiel and then became professor of English linguistics at Aarhus University 18 years ago, experimental linguistic work in the humanities was seen by some of my (former) colleagues as just not belonging in the humanities. One challenge that remains is that intelligent and interested language students who want to do L2 speech research lack the methodological and analytical background which other students from, for example, psychology may have with respect to statistics and research design. My colleagues and I are working on improving this situation, but it's an uphill battle. Regarding the advantages, I could go on for hours and hours, so here's just what springs to my mind first, which is that L2 speech research is almost always done in collaboration with colleagues, and that these colleagues very often have backgrounds that are different from one's own. You learn a lot, sometimes you can also contribute to joint research efforts, and, very importantly, it's intellectually stimulating and very often a lot of fun. Connected with this is a pervasive broad-minded attitude of leading researchers in our field. I have collaborated both with Jim Flege and with Cathi Best on studies which did not fully support their models. It would never have crossed their mind to bury these studies because the results were somehow inconvenient. Rather, they have been and would be the first to admit that their models need to confront the challenge presented by the data. Two other great advantage of our field, which no doubt can be a great motivation for junior researchers, are that much of what we do has never been done before, and that it is almost always very easy to explain to laypeople why we do what we do. I know several colleagues in the humanities who are quite envious of the ease with which we can justify research on L2 speech.

\section{Interviewers:}

Could you describe two of your main research findings and their implications to L2 teaching and learning? 


\section{Professor Ocke Bohn:}

The two of my research findings which I think are most important are both the results of serendipity - not expected on the bases of hypotheses which my colleagues and I had entertained. I think some would call this the "who ordered that?" effect.

The first of these resulted from a study which Jim Flege and I did on the perception of English vowel contrasts by various nonnative groups, including native speakers of German and of Spanish. The participants identified stimuli from a 'beat-bit' continuum and a 'bet-bat' continuum in which both vowel quality (spectrum) and vowel quantity (duration) varied. Our quite reasonable assumption was that German listeners, whose native language uses duration as a secondary cue to differentiate most vowel contrasts, would transfer their use of duration to English and also use duration (and spectrum) as a cue to differentiate English vowel contrasts. In Spanish, however, vowels differ only in quality, not in duration, so we expected that native Spanish listeners would not use the duration cue to differentiate English vowels. The German listeners did as expected, but the Spanish listeners relied almost exclusively on duration to differentiate the English 'beat-bit' contrast.

Why would they do that? It is certainly not something that is transferred from their native language. I tried to account for this with the Desensitization Hypothesis, which states that "whenever spectral differences are insufficient to differentiate vowel contrasts because previous linguistic experience did not sensitize listeners to these spectral differences, duration differences will be used to differentiate the nonnative vowel contrast" (BOHN, 1995). I consider myself lucky that quite a few of my colleagues in L2 speech research have found this hypothesis interesting and tested it on a number of L1-L2 combinations, including L2 Dutch and L1 Spanish, L2 German and L1 Turkish, and L2 English with a range of L1s including Mandarin, Portuguese, Russian, Polish, and Catalan. While the phenomenon that I first described is thus very robust, alternative accounts for it have been advanced. Whether in the end my account (desensitization) or other accounts can explain what is happening in L2 vowel perception doesn't really matter (to me). I am much less interested in being right than in providing food for thought for me and my colleagues.

Another main research finding resulted from the infant vowel perception research which I conducted with Linda Polka. In the first series of 
experiments on which we collaborated, we tested the assumption that the development of infant vowel perception would be similar to that for consonants, except that the shift from universal to language-specific vowel perception would occur earlier for vowels. The Canadian and German babies had several surprises for us in stock. The biggest of these was that they showed perceptual asymmetries which were the same irrespective of the age of the infants (6-8 months, 10-12 months) and of the ambient language (English or German). In general, perceptual asymmetries are interesting because a) they appear illogical, and b) they may tell us something about how the human mind processes stimuli. To give just one example, our infants (both language groups, both ages) discriminated a change from front rounded $/ y /$ to back rounded /u/ quite well, but were not good at discriminating a change from $/ \mathrm{u} /$ to $/ \mathrm{y} /$. Very odd!

Perceptual asymmetries had been observed before (also in other completely unrelated domains such as lexical semantics), but Linda Polka and I were the first who tried to come up with a coherent account of asymmetries in vowel perception in infants, in later development, and in nonnative speech perception by adults. This resulted in our Natural Referent Vowel (NRV) framework, which - in a nutshell - states that vowels that are relatively more peripheral in the human vowel space (such as /u/ vis-à-vis /y/) have a special status in what one might call "immature" vowel perception by infants and L2 learners. The predictions of NRV have been supported by almost all studies which have reported perceptual asymmetries, and NRV has also correctly predicted that these asymmetries disappear once a vowel contrast (such as $/ \mathrm{u} /-/ \mathrm{y} /$ ) has become functional in the learner's sound system. More recently, perceptual asymmetries have also been observed for consonants, but the results to date provide food for thought rather than a coherent picture.

\section{Interviewers:}

How do you see the future of the field of L2 phonetics or phonology?

\section{Professor Ocke Bohn:}

I find it difficult to come up with predictions, especially about the future, but here we go: Regarding research, I think we have almost reached a peak and plateau in terms of the democratization/availability of tools. I am old enough to remember the not-so-distant past when valuable lab time had to be reserved to work with very expensive, very big, and very slow equipment 
like a PDP11/73 "minicomputer". Nowadays, thanks to people like Paul Boersma \& David Weenink (Praat), James Hillenbrand (Alvin), Steven Weinberger (Speech Accent Archive), Andreia Rauber and colleagues (TP speech perception software), and quite a few more, a very decent phonetics lab is at the fingertips of everyone with an internet connection. This has had and will continue to have consequences, most obviously for the much needed study of L1-L2 combinations which have been absent or underrepresented in L2 speech research. For a number of good reasons, English is still overrepresented among the L2 languages studied, but it would be very unhealthy if our knowledge of L2 speech and the models which try to account for it were based only on L2 English. Luckily, this is not the case, and the near-universal availability of phonetic tools will make the models stronger and our insights more reliable.

Regarding applications, I am sure that, right now, a not so small number of programming enthusiasts and also commercial companies are trying to get the most out of digital technologies for L2 learners by, for example, developing electronic displays for visual feedback and mobile devices that perhaps can assist in L2 learning. The challenges, complexities, and opportunities are probably greatest for L2 speech (as compared to, say, L2 vocabulary or morphology). I assume that the motivation of many software developers is curiosity and perhaps also a genuine desire to help those poor L2 speakers who are nearly unintelligible and/or feel discriminated because of their nonnative accent, but it is also well documented by, for instance, Murray Munro, that quite a few charlatans with no knowledge of L2 speech research, but a big interest in fast bucks, want to sell their accent reduction products. No matter whether the developers of apps are fraudulent or honest, I advocate a sober approach to the use of digital technologies in L2 speech learning. Let's evaluate them, and, if they pass the test, appreciate their possible function as learning aids, but remain aware of the fairly well documented fact that successful language learning seems to require human interaction with rich and varied input. For a very long time to come, digital technologies will not be able to compete with flesh and blood humans.

\section{Interviewers:}

What advice would you give students who are interested in embarking in a career in L2 phonetics or phonology? What are the benefits and challenges of being in this field? 


\section{Professor Ocke Bohn:}

The somewhat boring but useful advice that any senior person might give to youngsters will be along the lines of: read a lot, attend conferences, visit different labs, stay curious, learn the necessary skills to plan and run experiments, and run your own experiments (from scratch). In addition, and also very generally, I think it is important not to be afraid of making mistakes. Everyone who has been in the field for more than, say, 5 years, has an experiment or two in her/his files who they think isn't worth publishing, maybe because of some mistake in the planning and/or execution of the experiment that would be rather difficult to rectify, but often also because the results just don't seem to make sense. Of course it is much less risky for a tenured person to make mistakes than for a junior researcher with uncertain job prospects, but we all learn a lot from the mistakes of others and especially from our own mistakes.

The benefits are also the challenges, and vice versa. $\mathrm{L} 2$ speech science is a very multidisciplinary area, and L2 speech scientists may have backgrounds in linguistics (phoneticians and phonologists), in psychology, neurolinguists, applied linguistics, engineering, information technology, etc. Interacting with and learning from colleagues who share one's own interest, but who have a quite different background, can be gratifying and interesting, but also challenging. The biggest challenge, of course, is that in order to be a good L2 speech scientist, you might have to acquire some quite detailed knowledge of neighboring fields, including the ones just mentioned, but certainly also some statistics, and perhaps also some acoustics, anatomy, and physiology. Perhaps the greatest benefit for the intellectually curious is that we L2 speech scientists are almost always pioneers: For the very vast majority of studies in our field, one can say: This is the first study that looks at (fill in L1, L2, and phenomenon studied).

\section{Interviewers:}

We believe that you are one of the few researchers (if not the only one) who has attended every meeting of the International Symposium on the Acquisition of Second Language Speech (New Sounds) since its inception in 1990, organized by Allan James and Jonathan Leather at the University of Amsterdam. Can you tell us a bit about the history of the event and some of the highlights? What changes have you noticed in related fields since the advent of New Sounds? To refresh your memory, here is a list of all previous (and forthcoming) New Sound events, followed by the name of the organizers: 
1990 - University of Amsterdam (Allan James \& Jonathan Leather) 1992 - University of Amsterdam (Allan James \& Jonathan Leather) 1997 - University of Klagenfurt (Allan James \& Jonathan Leather) 2000 - University of Amsterdam (Allan James \& Jonathan Leather) 2007 - Federal University of Santa Catarina, Florianópolis (Barbara Baptista, Michael Watkins, Andréia Rauber)

2010 - Adam Mickiewicz University (Katarzyna Dziubalska-Kołaczyk, Magdalena Wrembel, Małgorzata Kul)

2013 - Concordia University (Walcir Cardoso \& Pavel Trofimovich) 2016 - Aarhus University (Ocke-Schwen Bohn)]

\section{Professor Ocke Bohn:}

I think that Steven Weinberger is the other living fossil who has attended all New Sounds meetings since 1990, and Katarzyna Dziubalska-Kołaczyk, who most certainly is not a fossil, may also have attended all New Sounds meetings.

The New Sounds conferences very much reflect the development of the field - in terms of the numbers of participants, the topics covered, and in the way colleagues communicated their results. New Sounds started out as a small and intimate meeting in 1990. I think there were more or less 40 participants, and approximately 30 presentations at the first New Sounds meeting. At that time, the 40 participants represented a sizeable proportion of the L2 speech community - probably the majority of the European community, plus a few North Americans. The first two meetings in Amsterdam were small enough that every presentation was a plenary. This changed as of 1997, when poster and parallel sessions were introduced to accommodate all contributors. (I would like to add, as a footnote, that, for me, a poster does NOT rank below an oral presentation. I am aware that many think that oral presentations are more prestigious than poster presentations, but other international meetings like those of the Acoustical Society of America indicate that this is not the case. If a presenter wants detailed feedback - and most want this - then poster should clearly be the preferred form of presentation.)

The first four New Sounds differ in two ways from the later ones: There were no keynotes, and these early New Sounds were perceived to be a European forum, even though quite a few colleagues from exotic locations participated, like, for instance, Jim Flege. This changed in 2007, when New 
Sounds resurrected in Brazil after a seven-year hiatus through the efforts of Barbara Baptista, Michael Watkins, and Andréia Rauber. There were keynotes, there were parallel sessions and poster sessions, and, most importantly, New Sounds had now become the global (not just European) forum for L2 speech science.

The 2010 (Poznan) and 2013 (Montreal) New Sounds, with approximately 200 participants each, have clearly put New Sounds on the map as the prime meeting place for anyone interested in L2 speech. The one question that I heard again and again in Poznan and in Montreal from colleagues who had never before attended New Sounds meetings before was: "Why didn't I attend previous meetings?". The quality of oral and poster presentations is high, the organizers of all previous New Sounds have done a great job, and the atmosphere at all New Sounds was collegial and friendly.

It won't be easy for me to live up to the standards set by previous New Sounds meetings when I organize New Sounds in 2016 in Aarhus, but I am sure that the quality of submissions will be such that anyone interested in L2 speech will not want to risk missing out on new and exciting developments in our field. New Sounds 2016 in Aarhus should be enlightening, not the least because Aarhus offers approximately 20 hours of daylight (every day!) in mid-June, when the conference will be held.

Recebido em: 22/03/2015. Aceito em: 22/03/2015. 